\title{
Artigo
}

\section{Las narrativas del desarrollo en América Latina y la nueva gramática social del neocapitalismo}

Narratives of development in Latin America and the new social grammar of neocapitalism

\author{
José Solano Alpízar \\ Profesor de Universidad Nacional, Costa Rica \\ josesolanoalpizar@gmail.com
}

Resumen: El complejo proceso de transformaciones que comenzó a experimentar el mundo moderno en la segunda mitad del siglo XX, explica y se explica en el marco de un nuevo proceso de expansión del sistema capitalista, que ha tenido como uno de sus rasgos más significativos el uso y la apropiación del lenguaje como instrumento para transmitir una visión del mundo que atraviesa la cultura, las mentalidades y las subjetividades. Visión del mundo que ha logrado imponer su hegemonía discursiva desplazando a una gramática social contra-hegemónica que - durante poco más de medio siglo - sirvió para comprender y explicar la realidad histórico-social en América Latina.

Palabras-clave: Hegemonía discursiva; gramática social; neoliberalismo; lenguaje; globalización.

Abstract: The complex process of transformation that the modern world began experiencing in the second half of the twentieth century, explain and is explained in the framework of a new process of expansion of the capitalist system, which has as one of its most significant features the use and the appropriation of language as a tool for conveying a worldview that moves across culture, mentalities and subjectivities. Worldview that has succeeded in imposing its discursive hegemony displacing a counter-hegemonic social grammar - during over half a century - served to understand and explain the historical and social reality in Latin America.

Keywords: discursive hegemony; social grammar; neoliberalism; language; globalization.

"El lenguaje es por esencia la imposición de un orden aplicado al desorden de los fenómenos que rodean la existencia humana. La palabra crea realidad, la palabra es por esencia poder, poder sobre las cosas, pero también poder sobre los hombres, capacidad de organizar el mundo, codifica tanto lo social como lo natural"

Gusdorf 


\section{Introducción}

Existe una serie de procesos socio-culturales, económicos, políticos y epistémicos que nos son presentados como naturales, lógicos y necesarios. Este es el caso de los procesos que explican y acompañan la nueva etapa de expansión del sistema capitalista, la cual ha sido presentada bajo la etiqueta de "globalización", narrativa con la que se justifica el nuevo programa de dominación de clase en el que se impone el capital sobre el trabajo. El develamiento de los procesos y las operaciones semánticas que posicionan a la narrativa de la globalización - y la concepción de desarrollo que le es propia - como la hegemónica, constituye una tarea ineludible en cualquier esfuerzo por pensar otro mundo posible, pues uno de los terrenos en donde se dirime la lucha de clases en la actualidad es precisamente el ámbito del lenguaje.

En virtud de ello es que este ejercicio de descolonización epistemológica parte de la premisa de que una de las mayores luchas del siglo XX ha tenido lugar en el campo del lenguaje, pues la nueva dominación de clase ha tenido como uno de sus principales bastiones la creación y diseminación de nuevos significados, así como la apropiación de otros que eran empleados por la clase trabajadora y el pensamiento progresista, y que hoy han venido siendo resignificados por la intelectualidad orgánica al servicio del gran capital en el proceso de instauración de una nueva hegemonía discursiva.

En este entendido, cualquier esfuerzo de organización societal inscrito en el marco de un nuevo horizonte civilizatorio, pasa no sólo por la implementación de nuevas experiencias (postdesarrollo, Sumak Kawsay etc), sino también por el develamiento y puesta en cuestión de las formas en que se impuso la narrativa de la globalización y las operaciones semántico-epistémicas que provocaron la pérdida de capacidad explicativa y la potencia enunciativa de las narrativas sobre el desarrollo que pervivieron en América Latina por más de cuatro décadas.

\section{Lenguaje y poder: a propósito de la nueva gramática social del neocapitalismo}

El lenguaje y el poder se encuentran indisolublemente ligados en la historia humana; sin embargo, no es sino, en el siglo XX que esta relación adquiere una dimensión 
insospechada, particularmente por la toma de conciencia de la clase capitalista acerca del papel del lenguaje en los procesos de dominación social y la perpetuación del sistema. Dicha toma de conciencia tendrá expresión concreta al insertarse dentro de un nuevo programa de dominación de clase que comienza a ser impulsado a partir de la segunda mitad de este siglo por medio de diferentes "gabinetes de estrategia", 1 dentro de los que destacan la Sociedad Mont Pelerin, la London School of Economics, la Escuela Económica de Chicago, la RAND Corporation y CATO, entre otros.²

Durante el último cuarto del siglo XIX y la primera mitad del siglo XX, el liberalismo tuvo que afrontar duras batallas frente a los movimientos sociales y políticos aglutinados alrededor de las ideas y propuestas político-ideológicas planteadas por el socialismo, el comunismo y la socialdemocracia, por mencionar algunos; todas las cuales, sirvieron para potenciar el papel del trabajo respecto del voraz dominio que ejercía el capital. Producto de los estragos de la primera gran guerra mundial imperial, y los avances de estos movimientos políticos y sociales de la clase trabajadora, la clase capitalista se vio obligada a ceder terreno ante sus demandas, realizando para ello un tenue, pero significativo viraje "hacia la izquierda" para poder mantener el control sobre las estructuras de poder que daban fundamento a su dominación.

Ciertamente el conjunto de reformas de tipo socialista que tuvo lugar en el periodo de entreguerras propició un capitalismo menos "cruel y violento" que se mantendría relativamente estable hasta mediados de la década del 1970, momento en que las propias contradicciones del sistema y la presión de la clase trabajadora por mejorar sus condiciones de vida le servirían de condición de posibilidad para el despliegue de una sistemática y articulada contraofensiva ideológico-política y económica en la que se producirá una reestructuración del sistema capitalista, que estará caracterizada por un

El concepto "tanque de pensamiento" o "think tank" como se les conoce en lengua inglesa, refiere a la idea de agrupaciones intelectuales reunidas en centros de investigación, universidades, partidos políticos, organizaciones privadas etc., cuyos objetivos varían de un grupo a otro, pero que en la mayoría de los casos están dirigidos a influir sobre la opinión pública promoviendo puntos de vista específicos y con una carga ideológica también específica.

2 La Sociedad Mont-Perélin (1947) constituye uno de los primeros "tanques de pensamiento" en el siglo XX y el lugar donde se concretaría en parte el proyecto político de "compromiso con la libertad" conducente a la emergencia del neoliberalismo. Antes de ella se había dado un intento de creación de un tanque de pensamiento dirigido por F. von Hayek en la década del 1920, el cual era financiado por la Fundación Rockefeller, que buscaba desarrollar investigación empírica de manera independiente. Al respecto véase: José Francisco Puello-Socarrás (2007), Gramática del neoliberalismo. Genealogía y claves para su desciframiento. En: Economía, Gestión y Desarrollo, n. 5, Diciembre, pp. 177-204, Cali, Colombia. 
violento proceso de ajuste estructural a los requerimientos del capital en el marco de la llamada "globalización" (Petras y Veltmeyer, 2003).

Esta reestructuración del sistema capitalista, que ha tenido lugar en el último cuarto de siglo XX y se ha expresado de distintas maneras (económica, política, social, ideológica, tecnológica, cultural y militar), ha tenido su correlato a nivel semántico-discursivo, pues la contraofensiva neoliberal en lo económico y neoconservadora en lo político ha estado acompañada de una nueva gramática social que ha tenido la fuerza enunciativa y las condiciones de producción necesarias para desplazar del imaginario societal latinoamericano una serie de imágenes, conceptos y teorías que servían para explicar el carácter dependiente de los países de la América Latina (Solano, 2013).

Si bien podemos situar esta contraofensiva en el último cuarto de este siglo, su proceso de gestación es de más larga data, pues ya en el propio proceso de entreguerras la Sociedad Mont Pelerin, que aglutinaba a una serie de intelectuales conservadores y liberales (Von Mises, Von Hayek, Friedman, Popper, Aarón, Becker, entre otros), comenzó a generar una verdadera batalla ideológica en la que la semántica comienza a jugar un papel determinante. A partir de ese momento comenzó el proceso que habría de llegar a desplazar al keynesianismo del mapa político-económico y a las narrativas progresistas que habían venido desarrollándose a lo largo de la segunda mitad del siglo XX en América Latina y el resto del mundo. Como consecuencia directa de esto, en las últimas décadas de este siglo comienza a producirse un "giro gramático", en el que se produce un cambio decisivo en lo que podríamos llamar la "correlación de fuerzas discursivas" a favor de las narrativas que naturalizan el sistema-mundo capitalista.

Dicho giro lo podemos entender como un cambio en la gramática social de una época en el que se produce una serie de transformaciones semánticas que llevan a que nociones y conceptos que otrora servían para explicar la realidad, sean desplazadas del lenguaje, mientras que otras vienen a situarse en el nuevo espacio discursivo. Destacan en este giro una serie de estrategias semántico-discursivas mediante las cuales se produce la borradura de conceptos cuya carga enunciativa refiere a una gramática socialmente comprometida, así como la exclusión/inclusión de conceptos y nociones, y la creación de nuevos conceptos, por mencionar algunas de las operaciones con las que se ha logrado imponer hegemónicamente la narrativa de la globalización y la nueva gramática social del neocapitalismo. 
Es en este contexto histórico que ha tenido lugar el posicionamiento hegemónico de la narrativa de la globalización, en la que la apropiación del sentido por el poder ha logrado desplazar del imaginario social las visiones "socialmente críticas" sobre el desarrollo y la organización de la sociedad e instalar una nueva gramática social que, inspirada en la semántica mercantil, ha logrado posicionar la idea de un cambio de época y con ello el ocultamiento de un nuevo proceso de expansión del sistema capitalista.

Esta nueva gramática social invadió el espacio societal latinoamericano, desplazando, anulando e invisibilizando una serie de sustantivos críticos que habían servido para construir en el imaginario social la creencia de que era posible elaborar respuestas para un "desarrollo autóctono", capaz de permitir una vinculación territorial y culturalmente diferenciada con el sistema capitalista, de suerte tal, que generó un conjunto de metáforas con las que se buscaba representar la realidad (sociedad del conocimiento, sociedad postindustrial, aldea global, fin de la historia) y hacen su irrupción y desaparecen o se vacían de sentido conceptos que daban contenido a teorías y enfoques socialmente comprometidos: clase, dominación, libre autodeterminación, soberanía, justicia social, distribución equitativa de la riqueza, solidaridad, pueblo etc.

A este respecto, y coincidiendo con Bourdieu y Wacquant, en todos los países avanzados, empresarios, funcionarios internacionales, intelectuales mediáticos y periodistas de alto vuelo se pusieron de acuerdo para hablar un neolenguaje, cuyo vocabulario, aparentemente surgido de la nada, está en todas las bocas: "mundialización", "flexibilidad", "gobernabilidad" y "empleabilidad" (2000: 1). La aparición de esta neolengua obedece al hecho de que el lenguaje se constituye en parte importante del nuevo orden económico internacional, pues como apunta Fairclough (2000), el nuevo orden presupone un nuevo uso y apropiación del lenguaje, en tanto es éste el vehículo más adecuado para crear y recrear la visión de mundo de aquellos que no sólo se benefician de este orden, sino que continúan realizando ingentes esfuerzos por extenderlo.

No es fortuito por lo tanto que de manera sistemática, y como parte de una estrategia común, fundaciones, centros de investigación, asociaciones empresariales, agencias internacionales y estatales, entre otras, comprendan que es necesario copar todos los espacios sociales con un discurso creíble y aceptable para la población; es así como comienza el proceso de diseminación del nuevo ideario neoliberal y de la filosofía política que le es consustancial. 
De ésta manera, el capitalismo construye un nuevo lenguaje, su lenguaje, con un vocabulario procedente de la semántica mercantil, donde el proceso que conlleva a la tiranía del capital sobre el trabajo experimenta ahora una transformación radical, de manera que más allá de la coacción y el uso de la fuerza comúnmente utilizados para el control ciudadano, emerge la potencia de la palabra para concitar la unidad nacional, unir voluntades, prometer futuros venturosos y sobre todo una vida llena de éxito y felicidad sustentada en el placer del consumo inmediato.

\section{Algunas operaciones semántico-discursivas}

Como parte fundamental de lo que hemos venido señalando, es preciso destacar tres operaciones que ilustran el despliegue semántico con que el capitalismo ha logrado instaurar la hegemonía discursiva, desplazando los sustantivos críticos con que se concebía y explicaba la realidad social latinoamericana: la sustitución de conceptos, la apropiación de conceptos y la creación de nuevos conceptos.

En el primer caso se trata de una operación con la que se busca ocultar conceptos cuya carga enunciativa genera malestar y rechazo por parte de amplios sectores sociales; de ahí que se realice una acción de encubrimiento de estos conceptos y se le sustituya por otros que tienen la particularidad de que son significantes que no poseen una carga semántica negativa aún. Dicho de otro modo, se trata de vocablos que surgen para generar determinadas representaciones mentales positivas que son aceptadas e incluso reproducidas en diferentes ámbitos societales gracias a un sofisticado sistema de diseminación en el que existen personas y entidades encargadas de popularizar términos hasta hacerlos parte del sentido común y el habla cotidiana.

El concepto de "globalización" es un ejemplo claro de ello. El mismo viene a sustituir un concepto ampliamente analizado y rechazado en determinados círculos intelectuales, sociales y políticos; nos referimos al concepto de "imperialismo", el cual no sólo fue ampliamente analizado en la obra de Marx, sino también en la de los clásicos del imperialismo (Lenin, Luxemburgo, Kaustky, Hobson, Hilferding) y por supuesto ampliamente debatido por sectores intelectuales de ascendencia progresista en todo el mundo. Su introducción tiene un sentido encubridor, pues, como lo señaló Galbraith en su momento, el de globalización es un término creado por los Estados Unidos para 
promover su expansión imperialista; es decir, no es otra cosa que una nueva forma de imperialismo.

En este entendido, el concepto de globalización aparece como una construcción de sentido capaz de generar imágenes deseables en el imaginario social latinoamericano (y mundial), pues se presenta como una promesa de futuro, como un momento a alcanzar en el que los ciudadanos podrán acceder a todo aquello que no fue posible obtener debido a la presencia de Estados interventores que limitaban la acción individual y el disfrute pleno de los beneficios que traía consigo una economía internacionalizada. De esta manera, articulado a partir de una serie de encadenamientos semánticos con los cuales se construye una nueva representación del mundo, el concepto de globalización aparece como el substituto idóneo del concepto de capitalismo, el cual tiene un pesado lastre significativo, debido al cuestionamiento de que ha sido objeto el sistema y las formas de producción que ha promovido históricamente para la extracción de plusvalía.

Otro de los conceptos es el de "sociedad del conocimiento", término que ha tenido un largo recorrido para posicionarse en el imaginario social y particularmente en el mundo de la academia. Este concepto viene a sustituir al concepto de "capitalismo", pues con él se busca invisibilizar el hecho de que los procesos económicos, políticos, sociales etc., que ha venido experimentando el mundo moderno no son otra cosa que expresiones simbólico-materiales de la nueva etapa de expansión del sistema capitalista. Su popularización ha hecho que el término se convierta en moneda de curso común en la cotidianidad, alejando de la mente de los ciudadanos la negativa idea de capitalismo dibujada fantasmagóricamente en los primeros escritos marxistas, ello gracias a la introducción de numerosas imágenes que ponen de relieve la importancia trascendental del conocimiento y la tecnología (Lyotard, Drucker, Castells, Schaft), de tal manera que el conocimiento se concibe como un elemento igual o más importante que los otros elementos del proceso productivo (capital, trabajo).

Con esta operación se busca borrar del imaginario social la imagen de una sociedad desgarrada por la lucha de clases, donde unos son explotadores y otros son explotados y cambiarla por la imagen de un "mundo feliz y armónico" donde trabajadores y empleadores comparten los mismos valores, los mismos sueños, los mismos intereses. Hablamos, pues, de la nueva utopía capitalista, una sociedad donde campea la libertad 
de escoger y donde el Estado no es un lastre, sino un simple intermediario entre los consumidores y el mercado.

En el segundo caso nos referimos a una de las operaciones semántico-discursivas que mejor refiere al giro gramático que comienza a producirse a partir de la década del 1970, y la cual tiene que ver con la apropiación que tiene lugar en el lenguaje. Se trata de una operación mediante la cual significantes que han tenido una larga trayectoria en las ciencias sociales contemporáneas y se encuentran asociados con las luchas de las clases trabajadoras y los movimientos sociales progresistas y contestatarios, son vaciados de su significado original. Este es el caso del vocablo "progresista", pues de la noche a la mañana aparece el término "derecha progresista" utilizado en diferentes países del continente - México y Chile, por ejemplo -, y que en el caso chileno presenta a un partido político que en la propaganda electoral para la Presidencia de la República se autodenominaba "derecha progresista"; tal es el caso del partido Renovación Nacional, por otro lado, podemos destacar en este mismo país, el caso de los autoproclamados "progresistas", conocidos como la Concertación de Partidos por la Democracia, que sostenían el discurso de la "izquierda" y actuaban con la derecha, en una dinámica en que la que el "socialismo renovado" se constituye en un socialismo funcional al mercado globalizado.

Esta inversión del mundo de las ideas confunde y genera desconcierto entre una ciudadanía que no siempre se percata de la operación que lleva a concebir a los movimientos políticos y sociales asociados con la izquierda como expresiones retrógradas, y presenta a los conservadores de nuevo cuño como políticos de avanzada, capaces de promover la reforma social necesaria para el desarrollo nacional.

Otro concepto es el de "popular" empleado en la arena social y política contemporánea, ya que es notoria la forma en que los sectores tradicionales se han venido apropiando de un concepto que sirve para referir y aglutinar a la clase trabajadora. E concepto "popular" es un adjetivo que denota la pertenencia al pueblo; cuando se alude a él, generalmente evoca imágenes relacionadas con los sectores sociales menos afortunados y se asocia con imágenes que remiten a la idea de clase trabajadora, grupos de asalariados, grupos subalternos, que en nuestros países son los sectores que tienen menor posibilidad de acceso al poder y a la riqueza.

Esta operación semántica podría verse como una apropiación discursiva por parte de los sectores más tradicionales y conservadores, que utilizan dicho significante para 
aglutinar a los sectores populares alrededor de su programa de dominación de clase. Aunque el concepto guarda aquellos sentidos que refieren al pueblo y las grandes mayorías, el mismo sólo tiene importancia en la medida en que hace sentir a amplios sectores sociales que están representados por el ideario que un determinado grupo o partido les ofrece, y el cual oculta sus verdaderos intereses de clase. Esta operación tiene la clara intención de disputarle la representación de los intereses populares a los sectores de "izquierda" o en su defecto "progresistas", como es el caso del Partido Popular en España, que compite con el Partido Socialista por la representación de los sectores sociales cuya representación política se arrogaba este partido.

Finalmente, la tercera operación semántica es la de la creación de nuevos conceptos, pues la batalla por el lenguaje no termina con la sustitución o bien la apropiación de conceptos, pues una nueva operación que podemos rastrear es la de la creación de nuevos vocablos, más sonoros y seductores para una población ávida de novedades en un mundo que se le sugiere vertiginoso, caótico y fugaz. No podemos menos que reconocer la capacidad de la clase dominante capitalista en su afán de dominación global, pues en este esfuerzo ha tenido la capacidad de crear una política semántica claramente delimitada. Esta gramática provee de una batería terminológica que termina por encantar hasta a los más críticos gracias a la ayuda que brindan los escritos de algunos autores "postmodernos", que allanan el terreno para la sedimentación de dichos términos en los más variados ambientes societales, desde la academia hasta las entidades de gobierno, pasando por la ciudadanía en general que es bombardeada desde diferentes frentes por los medios de comunicación masiva y los nuevos divulgadores del credo neoliberal.

Conceptos como los de gobernanza, flexibilidad laboral, emprendedurismo y responsabilidad social empresarial se vuelven moneda de curso común en el habla cotidiana y gracias a ésta se asientan en el imaginario social de una manera casi naturalizada. Su empleo no es casual como tampoco es casual la intencionalidad de posicionarlos como parte constitutiva de la nueva gramática social del neocapitalismo, pues cada término se inscribe dentro de la misma matriz ideológico-política y promueve imágenes que se condicen con el ideario neoliberal en el que mercado e individuo ocupan un lugar medular. 
El concepto de "gobernanza" emerge en un momento de resurgimiento de la democracia liberal en los países de América Latina que estuvieron sojuzgados bajo la bota militar de las dictaduras. Con él se quiere significar un proceso sociopolítico dirigido por el Estado, con un alto grado de eficacia y calidad en todas sus actividades. Se le acuña en un momento histórico-social en que se quiere promover una "nueva forma de gobernar"; esto es, una forma de intervención estatal capaz de crear condiciones propicias para el buen desarrollo económico, la relativa estabilidad del sistema político y el incremento sostenido de la productividad (Banco Mundial, 1991, 2005, 2008).

De acuerdo con Dufour (2009), existe un notorio desplazamiento desde la noción moderna de gobierno a la noción postmoderna de gobernanza. Estas dos nociones son presentadas en la nueva narrativa como nociones opuestas, dejando entrever que la segunda (gobernanza) constituye la nueva forma en que debe tener lugar la organización económica en el mundo globalizado. Ciertamente, en el marco de diversas estrategias discursivas mediante las cuales se diseminan las ideas y valores de la narrativa de la "globalización", el concepto de gobernanza comienza a enunciarse reiteradamente como parte de la proliferación de vocablos provenientes del nuevo glosario mercantil y gerencial.

La idea de un "gobierno corporativo", en el que el capitalismo financiero comienza a ejercer su dominio y control, adquiere corporeidad gracias que se le logra vender a la ciudadanía la idea de que el Estado debe ser reducido y dedicado a tareas mínimas y al cual se le debe corresponder un nuevo tipo de gestión pública, caracterizado por el arribo de nuevos actores políticos que propenden por una regulación gubernamental "flexible", que favorezca las acciones privadas desde las propias esferas del mundo de lo público.

El concepto de gobernanza se aviene, de esta manera, con la lógica del capital y la filosofía política neoliberal, ya que esta apela a la idea de una "buena gestión" de los asuntos de la "res pública", donde tienen clara materialización los principios emanados del mal llamado "Consenso de Washington", como lo son el recorte del gasto público, el crecimiento de la inversión privada y la venta de activos manejados por el "viejo Estado de bienestar", entre otros. Al mismo tiempo, la idea de gobernanza presupone un desplazamiento de la acción ciudadana que opera bajo la concepción de gobierno, a una acción pasiva y despolitizada que opera en la lógica de la "sociedad civil", planteada por 
Hegel, según la cual "... los individuos son personas privadas que tienen como fin su interés propio" (Hegel, citado por Dufour, 2009).

De acuerdo con esta lógica, si el Estado es la instancia que permite el cumplimiento individual en el interés universal, en la medida que se cede a la idea de "gobernanza" se ceden los derechos que el Estado garantiza - con cierta igualdad de condiciones para pasar a una gobernanza de la "sociedad civil"; esto es, un nuevo espacio societal en el que los individuos se organizan, compiten y presionan por sus propios intereses bajo la lógica del darwinismo social.

El concepto de flexibilidad laboral es, por su parte, quizás, uno de los conceptos mayormente promovidos en la nueva narrativa, pues el mismo se condice con el asalto del capital al trabajo, ya que el mismo constituye un certero movimiento de la clase capitalista con respecto a las demandas de las clases trabajadoras. En efecto, la flexibilidad laboral como proceso y como práctica social viene a trastrocar el viejo esquema de negociación y relacionamiento empleador-empleado en la empresa fordista. El modelo de regulación laboral que ésta había permitido establecer - en el marco del pacto keynesiano - se ve ahora disuelto gracias a la estocada final que se le da a los derechos laborales del sector asalariado, que de la noche a la mañana amanece con nuevas reglas de contratación con las que se busca eliminar todas aquellas "trabas" u "obstáculos" que limitan la contratación o en su defecto el despido de un trabajador.

En resumidas cuentas, el concepto de flexibilidad laboral en lenguaje empresarial significa menor salario y menores garantías sociales. Es la culminación del sueño capitalista: tener libertad de contratar y despedir a placer, sin legislaciones laborales que lo impidan y sin un Estado que regule el proceso, pues para ello el mercado existe y tiene una ley muy clara - oferta y demanda. En este nuevo contexto histórico-epistémico, la narrativa de la "globalización" se ve alimentada por una serie de discursos de otro orden que promueven imágenes positivas sobre el nuevo cambio en la legislación laboral, el cual es visto ahora como la posibilidad de cambiar permanentemente de lugar de trabajo gracias a que cada persona puede alcanzar nuevas competencias que le permitan acceder a nuevos puestos sin temor de abandonar el que tenían.

Una de las ideas que se asocia con esta nueva etapa del neocapitalismo es precisamente la de que las personas pueden adquirir mejores calificaciones para el trabajo, refuncionalizando las viejas teorías del "capital humano" que proliferaron en la década 
del 1960 y 1970 (cfr. Solano, 2001). Esta idea de formación se asocia a la imagen de un mundo "volátil y cambiante", en el que se requiere de un personal con capacidad para renovarse de acuerdo con los requerimientos de la "sociedad del conocimiento", en un mundo que apuesta por valores como el riesgo, la innovación, la creatividad, la eficiencia, el éxito y el reciclaje laboral.

Estos valores encuentran eco en conceptos como los de "emprendedurismo" y "responsabilidad social empresarial", ya que ambos tienen un mismo punto de anclaje semántico, pues están relacionados con el esfuerzo sistemático por desplazar al Estado como ente articulador de la vida social y poner en su lugar al mercado, donde la agencia se encuentra a cargo del empresariado capitalista y los valores, creencias y tradiciones que este representa. La idea de que todos pueden aspirar a ser sus propios jefes y "emprender" aventuras empresariales esconde tras de sí la intención de romper con el llamado "paternalismo estatal", ya que el Estado se convirtió a lo largo del siglo XX en el principal empleador, y ahora que se ha producido su recorte y "adelgazamiento" es necesario trasladar la atención y las luces hacia la autogestión de los individuos y la acción de las empresas.

En la nueva narrativa se busca generar nuevas actitudes en los ciudadanos hacia el auto-empleo, promover que cada uno pueda ser su propio jefe y emprender su propio negocio, por ello se ofrecen imágenes bucólicas del ser empresario y de la misión de la "empresa privada" como productora de libertad, frente a un Estado interventor que limita la creatividad y la capacidad innovadora de los individuos. Asimismo, a la vez que se produce un reemplazo del concepto de capitalismo por el de "economía social de mercado", también se produce una operación mediante la cual se busca presentar un rostro humano y social de la empresa privada, rostro que no existe.

Con el concepto de "responsabilidad social empresarial", se realiza una especie de maquillaje con el que se busca presentar al empresariado como un agente socialmente comprometido con el bienestar de los individuos, las comunidades y la sociedad. En este sentido, el compromiso social empresarial forma parte de la estrategia que busca posicionar al empresariado como el agente central del desarrollo, una agencia que efectúa ingentes esfuerzos por innovar, atender las necesidades sociales de sus empleados y contribuir con el mejoramiento del medio ambiente. En este entendido, en la nueva narrativa la idea de compromiso social empresarial se presenta asociado a ideas como las 
de acción social y ética empresarial, de forma tal que se presenta al empresariado como el agente social por excelencia, cuya actividad trasciende la idea de mera ganancia para constituirse en un pilar fundamental del desarrollo económico y social.

No quisiéramos concluir estas reflexiones sin mencionar la fábula postmoderna. Al respecto quisiéramos decir que no nos encontramos en presencia de un cambio de época como se nos ha venido diciendo, tampoco hemos pasado de la modernidad a la postmodernidad. A nuestro modo de ver las cosas, esta es una nueva fábula con la que se disfraza el nuevo proceso de expansión del sistema capitalista a escala planetaria, en la que la intelectualidad al servicio o no del gran capital, promueve y disemina imágenes que se avienen con un proyecto político-cultural que presupone como objetivo nodal la reestructuración de la sociedad en dirección de lo que Polanyi denominará la "gran sociedad de mercado".

No estamos ante un cambio de época, como mal podría pensarse. Estamos ante una época de cambios en la que el giro lingüístico que tiene lugar en la década del 1970, ha servido de condición de posibilidad para el despliegue de una serie de planteamientos y reflexiones que contribuyen al afianzamiento del neoliberalismo y de la narrativa de la globalización. A este respecto, coincidimos con Heller, acerca de que lo postmoderno no es lo que sigue a la era moderna, sino "lo que le sigue a la evolución de la modernidad" (2000).

En este sentido, lo postmoderno es la expresión cultural de la nueva fase de expansión del sistema capitalista, le sirve para explicarlo y a la vez le abre nuevas posibilidades para proyectarse. A manera de ejemplo, cuando el "Happening" artístico surge en la década del 1970, con él irrumpe la imagen del momento fugaz tan propicio a la nueva discursividad cargada de figuras e imágenes que refieren a un mundo cambiante y en permanente transformación; un mundo del ahora, del ya, de un presente sin pasado, o por lo menos sin aquello del pasado que no se corresponde con los valores e intereses que suscribe e impulsa la nueva "gramática neoliberal".

El postmodernismo genera imágenes potentes sobre la vida, sobre la sociedad, sobre las relaciones humanas, sobre las emociones y los sentimientos, que apelan a una existencia efímera, afincada en el ahora, en la inmediatez, donde términos como líquido, flexible, vertiginoso, incierto, caótico, desechable y diverso se sedimentan en nuevas teorías que sirven para construir relatos que generan nuevas representaciones 
en el imaginario social. Sea que se hayan querido o no, algunos de los planteamientos postmodernos contribuyen a crear representaciones que son afines a los discursos que nutren la narrativa de la globalización; es así como discursos como el nihilista, la crítica a las certezas, la falta de sentido - de una u otra manera - han venido sirviendo de plataforma ideacional para que se afirme el individualismo neoliberal y aflore la pérdida de fe en la utopía liberadora, lo cual conduce a los sujetos a la conclusión de que la democracia liberal es el modelo máximo de organización humana³.

Enunciados como el "fin de la historia", el "fin de las ideologías políticas" y la "elección individual libre" construyen representaciones que se oponen a la visión solidaria y colectivista de las décadas anteriores, a las que el relato keynesiano les daba contenido. La visión fría, individual y autista - política y socialmente hablando - que orienta a la sociedad de consumo, termina por convertir a la ciudadanía en un sujeto pasivo, débil y fragmentado, que convertido en mero espectador ve en la democracia liberal el modelo ideal de organización social y político y al mercado como el mejor asignador de recursos.

La narrativa postmoderna constituye el nuevo caballo de Troya con el que el capitalismo ha logrado naturalizar una serie de imágenes e ideas que se sedimentan en el imaginario social. Con ella se ha construido la base cultural para su despliegue ideológico, político, económico y semántico. Por ello y coincidiendo con Ramos Pérez (2002: 108) el postmodernismo representa el imaginario socialmente necesario de la reestructuración social en curso, reestructuración que se desarrolla igualmente sobre el campo intelectual a través de luchas simbólicas intensas donde el punto central es la caracterización del momento actual de la civilización capitalista.

Ciertamente, el postmodernismo, en algunas de sus vertientes ofrece reflexiones y planteamientos que contribuyen a justificar las acciones del neoliberalismo y el neoconservadurismo, ya que las mismas les son funcionales a estas discursividades en la medida en que sirven para confundir a la gente. La anunciada muerte de los metarelatos pregonada por Lyotard ha ayudado notablemente a desprestigiar cualquier esfuerzo

El hecho de considerar que las principales tendencias del postmodernismo más afines a la nueva etapa de transformación del sistema capitalista y el posicionamiento hegemónico del neoliberalismo como patrón organizador de la vida societal han venido dominando el ambiente intelectual y comunicacional, no niega la existencia de propuestas alternativas al interior del postmodernismo cuyos planteamientos han venido contribuyendo a los esfuerzos emancipadores. Nos referimos a la obra de autoras y autores como Nelly Richards, Néstor García Canclini, Martín Barbero, Beatriz Sarlo, John Beverly, entre otros. 
por reivindicar el derecho a la esperanza y la posibilidad de un mundo posible fuera de la racionalidad instrumental del neoliberalismo.

La construcción de imágenes pletóricas de fatalismo no es algo casual, por ello se anuncian y popularizan metáforas como la del "fin de los metarelatos" (Lyotard), "el fin de la historia" (Fukuyama), "el fin de las ideologías" (Bell), "el enfrentamiento de culturas" (Huntington), "la muerte del estado-nación" (Ohmae), entre otras. Se trata de nuevas fábulas con las que se busca seducir a las "masas intelectuales" y a la ciudadanía en general, volcando su espíritu y su mente hacia la idea de la muerte de la modernidad y erigiendo la mal llamada postmodernidad como el nuevo paraíso de la ensoñación.

En virtud de ello, no consideramos que la modernidad se encuentre en proceso de disolución; por el contrario, creemos nuevamente con Heller que la postmodernidad viene a ser la toma de conciencia histórica de la modernidad. Es decir, una discursividad que - desde el plano sociocultural - contribuye y justifica muchos de los procesos y cambios que impone el nuevo proceso de expansión del sistema capitalista, pues en la urdimbre de significados que da sentido a la narrativa de la globalización se entrelaza con el discurso neoliberal y el discurso neoconservador.

La declaración del fin de la modernidad no es más que una estratagema ideológica con la que se busca romper los últimos bastiones éticos, políticos y sociales que le impiden al neoliberalismo liberar toda la fuerza destructora del capital. Es por ello que podemos observar el ataque irrestricto al Estado, a las formas de organización gremial y a las garantías sociales, entre otras, ya que estas refieren a formas de organización de la realidad que no se avienen con la nueva lógica de reproducción del capital.

Esta declaratoria de muerte de la modernidad busca cancelar el marco civilizatorio que dio lugar ésta, por lo menos en aquellos aspectos que no contribuyen al despliegue del capital en toda su extensión ${ }^{4}$. Es por ello que vemos emerger toda una batería de conceptos que vienen a alimentar el glosario elaborado por el neoliberalismo. Términos como multiculturalidad, diversidad, equidad, pluralidad, no son inocentes; por el contrario, poseen una carga enunciativa en el marco de determinados relatos que

Si bien es cierto el postmodernismo no es un movimiento monolítico, podemos afirmar que las tendencias más afines con la gran transformación que ha experimentado la economía capitalista han sido categóricas en la declaración de muerte de la modernidad, ya que ello presupone la liquidación de una serie de ideales (igualdad, libertad, justicia social), que si bien no se han cumplido cabalmente con la modernidad, continúan teniendo vigencia en el actual horizonte civilizatorio de la humanidad. 
sirven para justificar al neoliberalismo, al restarle fuerza a otros constructos que refieren más bien a las luchas reivindicativas de la clase trabajadora y a la organización social.

Una de las operaciones semánticas más inteligentes de los últimos tiempos tiene que ver precisamente con la emergencia de conceptos que refieren a movimientos y luchas en los que se disipa o bien desaparece la lucha de clases, y en su lugar se presentan reivindicaciones que no tocan el corazón del sistema de expoliación y pillaje global que se ha venido imponiendo. No queremos decir que dichas luchas no sean importantes y fundamentales, pero no podemos perder de vista que en el programa de dominación de clase los movimientos no se dan azarosamente, y que muchas de las cosas que vemos suceder tienen sentido en el marco de estrategias específicas.

No es azaroso el hecho de que el discurso postmoderno presente dos caras, pues mientras que por un lado pone en el tapete de discusión temas como los de diversidad, ciudadanía y género, por el otro, declara la muerte de la modernidad y con ello la cancelación de las expectativas que están asociadas a ella; es decir, los ideales de libertad, igualdad y justicia social, que si bien es cierto no se han cumplido cabalmente con la modernidad, no por ello dejan de tener sentido en un mundo cada vez más salvaje y descarnado.

\section{A manera de cierre provisional}

Hoy día no cabe duda de la existencia de una nueva gramática con la que el neocapitalismo ha venido imponiendo su hegemonía discursiva a través de una narrativa como la de la globalización. Esta gramática condensa una serie de discursos de la más variada procedencia y linaje, y en la que al igual que en el viejo tango "cambalache" vemos unidos de manera particular ideas y conceptos procedentes de campos tan disímiles como el discurso liberal y el discurso conservador, la filosofía utilitarista, el protestantismo y el catolicismo, la política contractualista, el discurso de la economía clásica y el discurso sobre la democracia participativa, por mencionar algunos.

Se hace evidente que desde hace poco más de tres décadas la teoría crítica latinoamericana comenzó a perder el control sobre determinados espacios de enunciación en los que había tenido gran injerencia y desde donde se hacían circular numerosos y ricos conceptos e ideas cuya carga enunciativa contribuía a dibujar formas alternativas 
para entender y explicar la realidad social. Esta pérdida tiene un carácter multicausal y su explicación se encuentra en el anudamiento de una serie de procesos que deben ser analizados de manera pormenorizada con el objeto de construir explicaciones que nos permitan dimensionar la vastedad de la contrarrevolución neoliberal.

Sí el lenguaje ha servido de vehículo eficaz para construir el nuevo orden económico internacional, cualquier proyecto alternativo debe considerar como parte de su agenda de lucha el cambio en el lenguaje, pues todo cuestionamiento del nuevo orden pasa por un cuestionamiento del nuevo lenguaje empleado por el capitalismo avanzado para imponer su propia visión del mundo.

\section{Referencias bibliográficas}

BANCO MUNDIAL (2007). Strengthening World Bank Group Engagement on Governance and Anticorruption. World Bank. <http://go.worldbank.org/6HHK3NDGL0>. (2005). Economic Growth in the 1990s. Learning from a Decade of Reform. Washington, D.C.: World Bank. (1991). Relatório sobre o Desenvolvimiento Mundial. O desafio do desenvolvimiento. Brasil: Fundación Getulio Vargas/Banco Mundial.

BOURDIEU, P.; WACQUANT, J. L. (2000). Una nueva vulgata planetaria. Le Monde Diplomatique, mayo, n. 55. No ofrece numeración de páginas.

DUFOUR, D. R. (2009). Gobernanza Versus Gobierno. En: Cuadernos de Administración. Universidad del Valle, n. 41/ Ene-Jun, pp. 27-38.

FAIRCLOUGH, N. (2000). Representaciones del cambio social en el discurso neoliberal. En: Cuaderno de Relaciones Laborales. 16: 13-3, S.I.

HELLER, A. (2000). Historia y futuro ¿Sobrevivirá la modernidad? Barcelona: Ediciones Península. PETRAS, J.; VELTMEYER, H. (2003). Un sistema en crisis. La dinámica del capitalismo de libre mercado. México: Editorial Lumen.

PUELLO-SOCARRÁS, J. F. (2008). Nueva gramática del neoliberalismo. Itinerarios teóricos, trayectorias intelectuales, claves ideológicas. Bogotá: Facultad de Derecho, Ciencias Políticas y Sociales, Universidad Nacional de Colombia.

RAMOS PÉREZ, A. (2002). Globalización y neoliberalismo. Ejes de la reestructuración del capitalismo mundial y del Estado en el fin del siglo XX. México: Plaza y Valdés. 
SOLANO, J. (2013). Las narrativas del desarrollo en América Latina y la nueva gramática social del capitalismo avanzado. Tesis Doctoral. Facultad de Filosofía y Humanidades, Universidad Austral de Chile.

(2001). Educación y desarrollo en América Latina. Un análisis histórico-conceptual. Heredia, Costa Rica: Editorial Universidad Nacional.

Recebido: 15/4/2014

Aceito: $20 / 7 / 2014$ 